\title{
Human leukocyte antigen-G 3' untranslated region polymorphisms are associated with asthma severity
}

\author{
Cinthia C. Alves ${ }^{\mathrm{a}, *}$, Luísa K.P. Arruda ${ }^{\mathrm{b}}$, Fabíola R. Oliveira ${ }^{\mathrm{b}}$, Juliana D. Massaro ${ }^{\mathrm{b}}$, \\ Beatriz J. Aquino ${ }^{\mathrm{b}}$, Michelle A. Paz ${ }^{\mathrm{c}}$, Erick C. Castelli ${ }^{\mathrm{c}, \mathrm{d}}$, Celso T. Mendes-Junior ${ }^{\mathrm{e}}$, \\ Eduardo A. Donadi ${ }^{\mathrm{a}, \mathrm{b}}$ \\ a Department of Biochemistry and Immunology, Ribeirão Preto Medical School, University of São Paulo, Ribeirão Preto, SP, Brazil \\ ${ }^{\mathrm{b}}$ Department of Medicine, Ribeirão Preto Medical School, University of São Paulo, Ribeirão Preto, SP, Brazil \\ ${ }^{\mathrm{c}}$ São Paulo State University (UNESP), School of Medicine, Molecular Genetics and Bioinformatics Laboratory, Botucatu, SP, Brazil \\ ${ }^{\mathrm{d}}$ São Paulo State University (UNESP), School of Medicine, Department of Pathology, Botucatu, SP, Brazil \\ e Departamento de Química, Laboratório de Pesquisas Forenses e Genômicas, Faculdade de Filosofia, Ciências e Letras de Ribeirão Preto, Universidade de São Paulo, \\ Ribeirão Preto, SP, Brazil
}

A R T I C L E IN F O

\section{Keywords:}

Asthma

HLA-G

Susceptibility

MHC

Mild asthma

Severe asthma

\begin{abstract}
A B S T R A C T
Asthma is a genetically complex chronic inflammatory airway disorder, and according to disease pathogenesis, clinical manifestations may vary according to asthma severity. A gene region close to the human leukocyte antigen-G $(H L A-G)$ gene was identified as an independent susceptibility marker for asthma. Considering that the HLA-G immune checkpoint molecule may modulate inflammation, we evaluated the diversity of the HLA-G $3^{\prime}$ untranslated region ( $3^{\prime} \mathrm{UTR}$ ) in asthmatic patients stratified according to disease severity. We evaluate the entire HLA-G 3'UTR segment in 115 Brazilian patients stratified into mild $(n=29)$, moderate $(n=21)$ and severe asthmatics $(n=65)$, and in 116 healthy individuals. HLA-G 3'UTR typing was performed using Sanger sequencing. The multiple comparisons among patients stratified according to disease severity revealed several associations; however, after Bonferroni's correction, the following results remained significant: i) the $+3010 \mathrm{C}$ and $+3142 \mathrm{G}$ alleles were overrepresented in mild asthma patients when compared to controls; ii) the $+3010 \mathrm{G}$ and $+3142 \mathrm{C}$ alleles were overrepresented in severe asthma patients in comparison to patients with mild asthma. In conclusion, the $+3010 \mathrm{C} / \mathrm{G}$ and $+3142 \mathrm{C} / \mathrm{G}$ HLA-G $3^{\prime} \mathrm{UTR}$ variation sites were differentially associated according to asthma severity.
\end{abstract}

\section{Introduction}

Asthma is a heterogeneous chronic inflammatory disease, exhibiting various phenotypes (Gauthier et al., 2015). Asthma prevalence is increasing worldwide, and it has been predicted that by the year 2025, 400 million people will develop asthma worldwide (Global Initiative for Asthma, 2017). According to the 2017 Update of the Global Initiative for Asthma (GINA), asthma severity can be classified into mild, moderate and severe (Global Initiative for Asthma, 2017).

Asthma severity is retrospectively evaluated based on the treatment necessary to control symptoms and according to exacerbations after several months of follow-up, which may change along time. According to GINA steps 1 and 2 guidelines, mild asthma is well controlled requiring the need of short acting bronchodilators alone (step 1) or low intensity daily treatment, including low dose inhaled corticosteroid
(ICS) (step 2). Moderate asthma is asthma well controlled with step 3 treatment, requiring low dose of ICS plus long-acting beta2-agonist (ICS + LABA) as first line of therapy. Most patients with severe asthma needs high-dose ICS-LABA (Step 4) to avoid that disease becomes uncontrolled, and some patients require add-on therapies including antileukotrienes, anti-cholinergic agents, and therapy with anti-IgE (omalizumab) or anti-IL-5 (mepolizumab, reslizumab) monoclonal antibodies (Step 5) (Global Initiative for Asthma, 2017).

Mild asthma patients may present allergic response to allergens and an eosinophilic inflammation that is usually associated with a Th2 polarization profile (Holgate, 2012). Severe asthma patients may exhibit increased number of exacerbations, decreased response to corticosteroid therapy, neutrophilia with predominance of a Th17 cytokine profile (Bell et al., 2011) and a Th1 polarization, involving IFN- $\gamma$ production accompanied with a reduced Th2 and Th17 response (Gauthier

\footnotetext{
* Corresponding author at: Ribeirão Preto Medical School, University of São Paulo, 3900 Bandeirantes Avenue, Ribeirão Preto, SP, 14049-900, Brazil.

E-mail address: cinthiacalves@usp.br (C.C. Alves).
} 
Table 1

Clinical and laboratory features of the asthmatic patients, stratified according to disease severity.

\begin{tabular}{|c|c|c|c|c|c|}
\hline & Whole Group & Mild & Moderate & Severe & P-value \\
\hline Age, mean $( \pm S D)$ & $45.8(17.01)$ & $40.2(18.17)$ & 42.9 (19.09) & 49.2 (15.09) & $\mathrm{NS}^{\mathrm{a}}$ \\
\hline Gender (\%) & & & & & $\mathrm{NS}^{\mathrm{b}}$ \\
\hline Female & $82(71.30 \%)$ & $22(75.86 \%))$ & $17(80.95 \%)$ & $43(66.15 \%)$ & \\
\hline Male & $33(28.70 \%) \%)$ & $07(24.14 \%)$ & 04 (19.05\%) & $22(33.85 \%)$ & \\
\hline Skin Color & & & & & $\mathrm{NS}^{\mathrm{b}}$ \\
\hline White & $91(79.13 \%)$ & $24(82.76 \%)$ & $17(80.95 \%)$ & $50(79.13 \%)$ & \\
\hline Mulatto & $13(11.30 \%)$ & $04(13.79 \%)$ & $02(9.52 \%)$ & $07(11.30 \%)$ & \\
\hline Black & $11(9.57 \%)$ & $01(3.45 \%)$ & $02(9.52 \%)$ & $08(9.57 \%)$ & \\
\hline Atopy & & & & & $\mathrm{NS}^{\mathrm{b}}$ \\
\hline Yes & $83(72.17 \%)$ & $19(65.52 \%)$ & $16(76.19 \%)$ & $48(73.85 \%)$ & \\
\hline No & $16(13.91 \%)$ & $01(3.45 \%)$ & $03(14.29 \%)$ & $12(18.46 \%)$ & \\
\hline N/A & $16(13.91 \%)$ & $09(31.03 \%)$ & $02(9.52 \%)$ & $05(7.69 \%)$ & \\
\hline Skin Prick Test & & & & & $\mathrm{NS}^{\mathrm{b}}$ \\
\hline Positive & $74(64.35 \%)$ & $18(62.07 \%)$ & $16(76.19 \%)$ & $40(61.54 \%)$ & \\
\hline Negative & $19(16.52 \%)$ & $01(3.45 \%)$ & $03(14.29 \%)$ & $15(23.08 \%)$ & \\
\hline N/A & $22(19.13 \%)$ & $10(34.48 \%)$ & $02(9.52 \%)$ & $10(15.38 \%)$ & \\
\hline Total IgE, geometric mean (range)* & $182.4(7.06-6340.00)$ & $324.3(27.9-4396.0)$ & $139.3(7.06-3010.00)$ & $179.1(9.66-6340.00)$ & $\mathrm{NS}^{\mathrm{a}}$ \\
\hline \multicolumn{6}{|l|}{ Spirometry values } \\
\hline FVC $(\%$ predicted $)$, mean $( \pm S D)^{* *}$ & $85.3(19.70)$ & $101.2(13.40)$ & $92.0(13.70)$ & $76.9(18.90)$ & $<0.0001^{\mathrm{a}}$ \\
\hline FEV1 (\% predicted), mean $( \pm S D)^{* *}$ & $65.4(22.70)$ & $88.1(12.90)$ & $74.0(16.30)$ & $53.6(19.30)$ & $<0.0001^{\mathrm{a}}$ \\
\hline FEF $25-75$ (\% predicted), mean $( \pm S D)^{* *}$ & $37.8(25.90)$ & $60.0(20.90)$ & $44.5(20.80)$ & $27.0(22.90)$ & $<0.0001^{\mathrm{a}}$ \\
\hline FVC/FEV1 ( $\%$ observed), mean $( \pm \text { SD) })^{* *}$ & $61.2(17.80)$ & $74.2(11.00)$ & $67.2(15.80)$ & $53.9(17.00)$ & $<0.0001^{\mathrm{a}}$ \\
\hline Smoking habits & & & & & NS ${ }^{b}$ \\
\hline Yes & $10(8.70 \%)$ & $02(6.90 \%)$ & $02(9.52 \%)$ & $06(9.23 \%)$ & \\
\hline No & $75(65.22 \%)$ & $20(68.97 \%)$ & $17(80.95 \%)$ & $38(58.46 \%)$ & \\
\hline Ex-smoker & $25(27.69 \%)$ & $05(17.24 \%)$ & $02(9.52 \%)$ & $18(27.69 \%)$ & \\
\hline N/A & $05(4.35 \%)$ & $02(6.90 \%)$ & $0(0.00 \%)$ & $93(4.62 \%)$ & \\
\hline
\end{tabular}

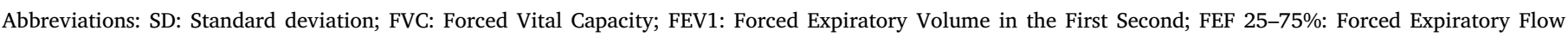
between $25 \%$ and $75 \%$ of the FVC; N/A: missing information in the medical records; NS: Non-significan.

Differences between groups were analyzed using the ${ }^{\mathrm{a}}$ Kruskal-Wallis test, followed by Dunn post hoc test, and the ${ }^{\mathrm{b}}$ chi-square test.

"This information was available for 64 patients in the medical records.

** This information was not available for 6 patients in the medical records.

et al., 2015; Raundhal et al., 2015).

As a heterogeneous genetically complex disorder, many immune and non-immune genes have been involved on asthma susceptibility, and the interaction of genetic predisposition with environment factors may account for the asthma phenotype (Kuhlen et al., 2014; Wenzel, 2012). Genome-wide association studies have disclosed several susceptibility genes associated with asthma, including ADAM33 (Disintegrin and metalloproteinase domain-containing protein-33), DPP10 (Inactive dipeptidyl peptidase-10), PTGDR (prostaglandin D receptor), CTNNA (Catenin alpha-3), IL1RL1 (Interleukin 1 receptor-like 1), PDE4D (cAMP-specific 3',5'-cyclic phosphodiesterase 4D), TLE4 (Transducin-like enhancer protein 4), DENND1B (DENN domain-containing protein $1 \mathrm{~B}$ ), and the genes of the Major Histocompatibility Complex (MHC), including HLA-DQ and HLA-DP alleles (Lee et al., 2015). Besides the association with MHC class II genes, a study conducted on a large number of asthmatic patient together with their families identified the $H L A-G$ gene region (6p21) as an independent susceptibility factor (Nicolae et al., 2005).

HLA-G is a non-classical histocompatibility class I molecule that plays a pivotal role on immune system regulation, acting as a checkpoint molecule. It is mainly expressed in the first and second trimester placental tissues, facilitating the maternal-fetal tolerance, inhibiting the cytotoxicity effects of T CD8 + and natural killer (NK) cells. However, HLA-G can expressed in several pathological conditions, such as cancer and viral infection, leading to the impairment of the immune response against tumor cells or pathogens (Morandi et al., 2016). Alternative splicing of the primary transcript may produce at least four membranebound (HLA-G1 to HLA-G4) and three soluble (HLA-G5 to HLA-G7) isoforms that modulate the immune system by interaction with inhibitory receptors (ILT-2 and ILT-4) present on the surface of several immune cells, including macrophages, monocytes, dendritic cells, $\mathrm{T}$ cells and NK cells (Donadi et al., 2011).

The HLA-G gene may be regulated by several transcriptional and post-transcriptional elements. Particularly, the $3^{\prime}$ untranslated region (3'UTR) exhibits several polymorphic sites that may influence the HLA$G$ expression profile by modifying mRNA stability and/or influencing the microRNAs (miRNA) binding to the mature mRNA (Rousseau et al., 2003; Tan et al., 2008; Yie et al., 2008). Individual patterns of HLA-G expression have been associated with HLA-G 3'UTR variation sites (Martelli-Palomino et al., 2013) and these variation sites have associated with many pathological situations, including autoimmune, chronic inflammatory and infectious disorders (Ciliao Alves et al., 2012; Dias et al., 2015; Donadi et al., 2011; Silva et al., 2013).

Considering that: i) HLA-G may modulate the severity of chronic inflammatory disorders (Morandi et al., 2016), ii) the inflammatory profile of asthmatic patients may be different according to asthma severity (Gauthier et al., 2015), and iii) a region close the $H L A-G$ gene has been associated with susceptibility to asthma (Nicolae et al., 2005), we studied the role of $H L A-G 3^{\prime} \mathrm{UTR}$ polymorphic sites and haplotypes, and their relationship with asthma severity.

\section{Material and methods}

\subsection{Subjects}

We studied 115 asthmatic patients ( 82 women), aged 9 to 82 years old (mean: 45.8 years, SD \pm 17.0 ), selected from the Allergy Clinics of the University Hospital of the Ribeirão Preto Medical School, University of São Paulo, Brazil. Patients were stratified according to disease severity into mild $(n=29)$, moderate $(n=21)$ and severe asthmatics ( $n=65$ ), according to the 2017 GINA guidelines (GINA, 2017).

Patients with severe asthma presented values of Forced Expiratory 
Table 2

Allele frequency of variations sites observed at $3^{\prime}$ untranslated region ( $3^{\prime} \mathrm{UTR}$ ) of $H L A-G$ gene in asthmatic patients stratified according to disease.

\begin{tabular}{|c|c|c|c|c|c|c|c|c|c|c|c|c|c|c|}
\hline \multirow{3}{*}{$\begin{array}{l}\text { Genotypes } \\
\text { and alleles } \\
\text { 14-bp-Del-Del }\end{array}$} & \multicolumn{2}{|l|}{$\mathrm{C}$} & \multicolumn{2}{|l|}{ W } & \multicolumn{2}{|c|}{ ML } & \multicolumn{2}{|c|}{$\mathrm{MD}$} & \multicolumn{2}{|l|}{ SV } & \multicolumn{2}{|c|}{$\mathrm{MD} / \mathrm{SV}$} & \multicolumn{2}{|c|}{$\mathrm{ML} / \mathrm{MD}$} \\
\hline & \multicolumn{2}{|c|}{$(n=116)$} & \multicolumn{2}{|c|}{$(n=115)$} & \multicolumn{2}{|c|}{$(n=29)$} & \multicolumn{2}{|c|}{$(n=21)$} & \multicolumn{2}{|c|}{$(n=65)$} & \multicolumn{2}{|c|}{$(n=89)$} & $\begin{array}{l}n \\
(n=\end{array}$ & Freq. \\
\hline & 41 & 0.3534 & 35 & 0.3043 & 6 & 0.2069 & 7 & 0.3333 & 22 & 0.3385 & 29 & 0.3372 & 13 & 0.2600 \\
\hline 14-bp-Del-Ins & 52 & 0.4483 & 66 & 0.5739 & 20 & 0.6897 & 9 & 0.4286 & 37 & 0.5692 & 46 & 0.5349 & 29 & 0.5800 \\
\hline 14-bp-Ins-Ins & 23 & 0.1983 & 14 & 0.1217 & 3 & 0.1034 & 5 & 0.2381 & 6 & 0.0923 & 11 & 0.1279 & 8 & 0.1600 \\
\hline 14-bp-Ins & 98 & 0.4224 & 94 & 0.4087 & 26 & 0.4483 & 19 & 0.4524 & 49 & 0.3769 & 68 & 0.3820 & 45 & 0.4500 \\
\hline$+3001 \mathrm{C}-\mathrm{C}$ & 114 & 0.4914 & 113 & 0.9826 & 28 & 0.9655 & 21 & 1.0000 & 64 & 0.9846 & 85 & 0.9884 & 49 & 0.9800 \\
\hline$+3001 \mathrm{C}-\mathrm{T}$ & 2 & 0.0086 & 2 & 0.0174 & 1 & 0.0345 & 0 & 0.0000 & 1 & 0.0154 & 1 & 0.0116 & 1 & 0.0200 \\
\hline$+3001 \mathrm{~T}-\mathrm{T}$ & 0 & 0.0000 & 0 & 0.0000 & 0 & 0.0000 & 0 & 0.0000 & 0 & 0.0000 & 0 & 0.0000 & 0 & 0.0000 \\
\hline$+3001 \mathrm{C}$ & 230 & 0.9914 & 228 & 0.9913 & 57 & 0.9828 & 42 & 1.0000 & 129 & 0.9923 & 177 & 0.9944 & 99 & 0.9900 \\
\hline$+3003 \mathrm{C}-\mathrm{C}$ & 1 & 0.0043 & 3 & 0.0261 & 0 & 0.0000 & 1 & 0.0476 & 2 & 0.0308 & 3 & 0.0349 & 1 & 0.0200 \\
\hline$+3003 \mathrm{C}-\mathrm{T}$ & 29 & 0.1250 & 17 & 0.1478 & 2 & 0.0690 & 3 & 0.1429 & 12 & 0.1846 & 15 & 0.1744 & 5 & 0.1000 \\
\hline$+3003 \mathrm{~T}-\mathrm{T}$ & 86 & 0.3707 & 94 & 0.8174 & 26 & 0.8966 & 17 & 0.8095 & 51 & 0.7846 & 68 & 0.7907 & 43 & 0.8600 \\
\hline$+3003 \mathrm{~T}$ & 201 & 0.8664 & 207 & 0.9000 & 56 & 0.9655 & 37 & 0.8810 & 114 & 0.8769 & 157 & 0.8820 & 93 & 0.9300 \\
\hline$+3010 \mathrm{C}-\mathrm{C}$ & 36 & 0.1552 & 42 & 0.3652 & 17 & 0.5862 & 9 & 0.4286 & 16 & 0.2462 & 25 & 0.2907 & 26 & 0.5200 \\
\hline$+3010 \mathrm{G}-\mathrm{C}$ & 56 & 0.2414 & 42 & 0.3652 & 10 & 0.3448 & 5 & 0.2381 & 27 & 0.4154 & 32 & 0.3721 & 15 & 0.3000 \\
\hline$+3010 \mathrm{G}-\mathrm{G}$ & 24 & 0.1034 & 20 & 0.1739 & 1 & 0.0345 & 7 & 0.3333 & 12 & 0.1846 & 19 & 0.2209 & 8 & 0.1600 \\
\hline$+3010 \mathrm{C}$ & 128 & 0.5517 & 137 & 0.5957 & 45 & 0.7759 & 23 & 0.5476 & 69 & 0.5308 & 98 & 0.5506 & 68 & 0.6800 \\
\hline$+3027 \mathrm{~A}-\mathrm{A}$ & 0 & 0.0000 & 0 & 0.0000 & 0 & 0.0000 & 0 & 0.0000 & 0 & 0.0000 & 0 & 0.0000 & 0 & 0.0000 \\
\hline$+3027 \mathrm{C}-\mathrm{A}$ & 13 & 0.0560 & 6 & 0.0522 & 0 & 0.0000 & 3 & 0.1429 & 3 & 0.0462 & 6 & 0.0698 & 3 & 0.0600 \\
\hline$+3027 \mathrm{C}-\mathrm{C}$ & 103 & 0.4440 & 109 & 0.9478 & 29 & 1.0000 & 18 & 0.8571 & 62 & 0.9538 & 80 & 0.9302 & 47 & 0.9400 \\
\hline$+3027 \mathrm{C}$ & 219 & 0.9440 & 224 & 0.9739 & 58 & 1.0000 & 39 & 0.9286 & 127 & 0.9769 & 172 & 0.9663 & 97 & 0.9700 \\
\hline$+3032 \mathrm{G}-\mathrm{G}$ & 116 & 0.5000 & 114 & 0.9913 & 29 & 1.0000 & 21 & 1.0000 & 64 & 0.9846 & 85 & 0.9884 & 50 & 1.0000 \\
\hline$+3032 \mathrm{G}-\mathrm{C}$ & 0 & 0.0000 & 0 & 0.0000 & 0 & 0.0000 & 0 & 0.0000 & 0 & 0.0000 & 0 & 0.0000 & 0 & 0.0000 \\
\hline$+3032 \mathrm{C}-\mathrm{C}$ & 0 & 0.0000 & 1 & 0.0087 & 0 & 0.0000 & 0 & 0.0000 & 1 & 0.0154 & 1 & 0.0116 & 0 & 0.0000 \\
\hline$+3032 \mathrm{G}$ & 232 & 1.0000 & 228 & 0.9913 & 58 & 1.0000 & 42 & 1.0000 & 128 & 0.9846 & 176 & 0.9888 & 100 & 1.0000 \\
\hline$+3035 \mathrm{C}-\mathrm{C}$ & 87 & 0.3750 & 82 & 0.7130 & 19 & 0.6552 & 16 & 0.7619 & 47 & 0.7231 & 63 & 0.7326 & 35 & 0.7000 \\
\hline$+3035 \mathrm{C}-\mathrm{T}$ & 23 & 0.0991 & 31 & 0.2696 & 10 & 0.3448 & 5 & 0.2381 & 16 & 0.2462 & 21 & 0.2442 & 15 & 0.3000 \\
\hline$+3035 \mathrm{~T}-\mathrm{T}$ & 6 & 0.0259 & 1 & 0.0087 & 0 & 0.0000 & 0 & 0.0000 & 1 & 0.0154 & 1 & 0.0116 & 0 & 0.0000 \\
\hline$+3035 \mathrm{C}$ & 197 & 0.8491 & 197 & 0.8565 & 48 & 0.8276 & 37 & 0.8810 & 112 & 0.8615 & 149 & 0.8371 & 85 & 0.8500 \\
\hline$+3121 \mathrm{C}-\mathrm{C}$ & 0 & 0.0000 & 0 & 0.0000 & 0 & 0.0000 & 0 & 0.0000 & 0 & 0.0000 & 0 & 0.0000 & 0 & 0.0000 \\
\hline$+3121 \mathrm{~T}-\mathrm{C}$ & 1 & 0.0043 & 1 & 0.0087 & 0 & 0.0000 & 0 & 0.0000 & 1 & 0.0154 & 1 & 0.0116 & 0 & 0.0000 \\
\hline$+3121 \mathrm{~T}-\mathrm{T}$ & 115 & 0.4957 & 114 & 0.9913 & 29 & 1.0000 & 21 & 1.0000 & 64 & 0.9846 & 85 & 0.9884 & 50 & 1.0000 \\
\hline$+3121 \mathrm{~T}$ & 231 & 0.9957 & 229 & 0.9957 & 58 & 1.0000 & 42 & 1.0000 & 129 & 0.9923 & 177 & 0.9944 & 100 & 1.0000 \\
\hline$+3142 \mathrm{C}-\mathrm{C}$ & 24 & 0.1034 & 19 & 0.1652 & 1 & 0.0345 & 7 & 0.3333 & 11 & 0.1692 & 18 & 0.2093 & 8 & 0.1600 \\
\hline$+3142 \mathrm{C}-\mathrm{G}$ & 56 & 0.2414 & 53 & 0.4609 & 11 & 0.3793 & 5 & 0.2381 & 37 & 0.5692 & 42 & 0.4884 & 16 & 0.3200 \\
\hline$+3142 \mathrm{G}-\mathrm{G}$ & 36 & 0.1552 & 40 & 0.3478 & 15 & 0.5172 & 9 & 0.4286 & 16 & 0.2462 & 25 & 0.2907 & 24 & 0.4800 \\
\hline$+3142 \mathrm{G}$ & 128 & 0.5517 & 138 & 0.6000 & 45 & 0.7759 & 23 & 0.5476 & 70 & 0.5385 & 99 & 0.5562 & 68 & 0.6800 \\
\hline$+3187 \mathrm{~A}-\mathrm{A}$ & 66 & 0.2845 & 66 & 0.5739 & 21 & 0.7241 & 11 & 0.5238 & 34 & 0.5231 & 45 & 0.5233 & 32 & 0.6400 \\
\hline$+3187 \mathrm{~A}-\mathrm{G}$ & 36 & 0.1552 & 44 & 0.3826 & 8 & 0.2759 & 6 & 0.2857 & 30 & 0.4615 & 36 & 0.4186 & 14 & 0.2800 \\
\hline$+3187 \mathrm{G}-\mathrm{G}$ & 14 & 0.0603 & 5 & 0.0435 & 0 & 0.0000 & 4 & 0.1905 & 1 & 0.0154 & 5 & 0.0581 & 4 & 0.0800 \\
\hline$+3187 \mathrm{~A}$ & 168 & 0.7241 & 176 & 0.7652 & 50 & 0.8621 & 28 & 0.6667 & 98 & 0.7538 & 132 & 0.7416 & 78 & 0.7800 \\
\hline$+3196 \mathrm{C}-\mathrm{C}$ & 62 & 0.2672 & 57 & 0.4957 & 13 & 0.4483 & 9 & 0.4286 & 35 & 0.5385 & 44 & 0.5116 & 22 & 0.4400 \\
\hline$+3196 \mathrm{C}-\mathrm{G}$ & 45 & 0.1940 & 50 & 0.4348 & 14 & 0.4828 & 10 & 0.4762 & 26 & 0.4000 & 36 & 0.4186 & 24 & 0.4800 \\
\hline$+3196 \mathrm{G}-\mathrm{G}$ & 9 & 0.0388 & 8 & 0.0696 & 2 & 0.0690 & 2 & 0.0952 & 4 & 0.0615 & 6 & 0.0698 & 4 & 0.0800 \\
\hline$+3196 \mathrm{C}$ & 169 & 0.7284 & 164 & 0.7130 & 40 & 0.6897 & 28 & 0.6667 & 96 & 0.7385 & 130 & 0.7303 & 68 & 0.6800 \\
\hline$+3227 \mathrm{~A}-\mathrm{A}$ & 0 & 0.0000 & 0 & 0.0000 & 0 & 0.0000 & 0 & 0.0000 & 0 & 0.0000 & 0 & 0.0000 & 0 & 0.0000 \\
\hline$+3227 \mathrm{G}-\mathrm{A}$ & 5 & 0.0216 & 7 & 0.0609 & 3 & 0.1034 & 0 & 0.0000 & 4 & 0.0615 & 4 & 0.0465 & 3 & 0.0600 \\
\hline$+3227 \mathrm{G}-\mathrm{G}$ & 111 & 0.4784 & 106 & 0.9217 & 25 & 0.8621 & 21 & 1.0000 & 60 & 0.9231 & 81 & 0.9419 & 46 & 0.9200 \\
\hline$+3227 \mathrm{G}$ & 227 & 0.9784 & 223 & 0.9696 & 55 & 0.9483 & 42 & 1.0000 & 126 & 0.9692 & 174 & 0.9775 & 97 & 0.9700 \\
\hline
\end{tabular}

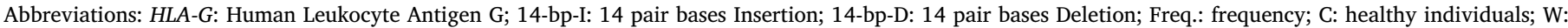

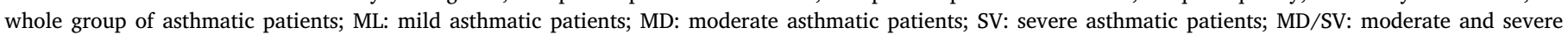
asthmatic patients group; ML/MD: mild and moderate asthmatic patients group.

Volume in One Second (FEV1) $<60 \%$; Forced Expiratory Flow (FEF) between $25 \%$ and $75 \%$ of the Forced Vital Capacity (FVC) FEF $25-75 \%<30 \%$; VEF1/CVF < 70\%; and severe exacerbations. Skin prick tests were carried out on patient forearm using a prick lancet, with a panel of inhalant allergenic extracts (FDA Allergenic, Rio de Janeiro, Brazil). Positive (histamine hydrochloride $10 \mathrm{mg} / \mathrm{mL}$ ) and negative (saline solution) controls were included in all tests. Skin prick tests were considered to be positive when a wheal of $\geq 4 \mathrm{~mm}$ accompanied by erythema developed $15 \mathrm{~min}$ following application of the extract. Total IgE levels $>100 \mathrm{UI} / \mathrm{mL}$ or the positive result of the skin prick test were considered to classify allergic status. Demographic and clinical features, spirometry values, skin prick test results and total IgE levels are shown in Table 1.

A group of 116 healthy individuals from the same geographic region, presenting age and ethnic characteristics compatible to the studied patients, was also evaluated. This group is a sample of a larger dataset, in which the entire $H L A-G$ variability was characterized in Brazil (Castelli et al., 2017) by using massive parallel sequencing procedures.

The study protocol was approved by the local Research Ethics Committee (Protocols \#12398/2004 and 6323/2011), and all subjects or their legal guardians gave written informed consent to participate in the study.

\subsection{Assignments of $3^{\prime} U T R$ HLA-G variation sites}

For patients, the identification of polymorphic sites at the HLA-G 3'UTR segment was performed using PCR-amplified DNA and Sanger sequencing, as previously reported (Castelli et al., 2010). 
Table 3

Comparison of allele frequencies of the $H L A-G 3^{\prime}$ untranslated region (3'UTR) polymorphisms. Significant results are highlightened in bold.

\begin{tabular}{|c|c|c|c|c|}
\hline Allele & Comparisons & P-value & OR & $95 \% \mathrm{CI}$ \\
\hline 14-bp-Del-Ins & ML versus $\mathrm{C}$ & 0.0232 & 2.7350 & 1.1485 to 6.5130 \\
\hline \multirow[t]{2}{*}{$+3003 \mathrm{C}-\mathrm{T}$} & ML versus $\mathrm{C}$ & 0.0414 & 0.2222 & 0.0498 to 0.9925 \\
\hline & MD/ML versus $\mathrm{C}$ & 0.0352 & 0.3333 & 0.1208 to 0.9198 \\
\hline \multirow[t]{2}{*}{$+3010 \mathrm{G}-\mathrm{G}$} & MD versus ML & 0.0067 & 14.0000 & 1.5647 to 125.2615 \\
\hline & SV/MD versus $\mathrm{ML}$ & 0.0029 & 7.9403 & 1.0133 to 62.2196 \\
\hline$+3010 \mathrm{G}-\mathrm{C}$ & MD/ML versus $\mathrm{C}$ & 0.0397 & 0.4592 & 0.2267 to 0.9303 \\
\hline \multirow[t]{5}{*}{$+3010 \mathrm{C}-\mathrm{C}$} & ML versus C & 0.0090 & 3.1481 & 1.3630 to 7.2716 \\
\hline & $\mathrm{MD} / \mathrm{ML}$ versus $\mathrm{C}$ & 0.0141 & 2.4074 & 1.2195 to 4.7525 \\
\hline & SV versus ML & 0.0022 & 0.2305 & 0.0910 to 0.5841 \\
\hline & SV/MD versus $\mathrm{ML}$ & 0.0069 & 0.2893 & 0.1208 to 0.6928 \\
\hline & SV versus $\mathrm{MD} / \mathrm{ML}$ & 0.0034 & 0.3014 & 0.1366 to 0.6651 \\
\hline \multirow[t]{6}{*}{$+3010 \mathrm{G}$} & ML versus C & 0.0025 & 0.3636 & 0.1860 to 0.7111 \\
\hline & MD/ML versus $C$ & 0.0384 & 0.5878 & 0.3586 to 0.9637 \\
\hline & SV versus ML & $0.0006^{*}$ & 3.4993 & 1.7122 to 7.1517 \\
\hline & MD versus ML & 0.0184 & 2.7960 & 1.1747 to 6.6551 \\
\hline & SV/MD versus $\mathrm{ML}$ & $0.0012 *$ & 3.3021 & 1.6543 to 6.5909 \\
\hline & SV versus $\mathrm{MD} / \mathrm{ML}$ & 0.0063 & 2.1647 & 1.2456 to 3.7622 \\
\hline \multirow[t]{6}{*}{$+3010 \mathrm{C}$} & ML versus $\mathrm{C}$ & 0.0025 & 2.7500 & 1.4063 to 5.3776 \\
\hline & MD/ML versus $C$ & 0.0384 & 1.7012 & 1.0377 to 2.7888 \\
\hline & SV versus $\mathrm{ML}$ & $0.0006^{*}$ & 0.2858 & 0.1398 to 0.5840 \\
\hline & MD versus ML & 0.0184 & 0.3577 & 0.1503 to 0.8513 \\
\hline & SV/MD versus $M L$ & $0.0012^{*}$ & 0.3021 & 0.1517 to 0.6045 \\
\hline & SV versus $\mathrm{MD} / \mathrm{ML}$ & 0.0063 & 0,4620 & 0.2658 to 0.8028 \\
\hline$+3142 \mathrm{C}-\mathrm{C}$ & MD versus $\mathrm{ML}$ & 0.0067 & 14.0000 & 1.5647 to 125.2615 \\
\hline \multirow[t]{2}{*}{$+3142 \mathrm{C}-\mathrm{G}$} & SV versus MD & 0.0116 & 4.2286 & 1.3828 to 12.9313 \\
\hline & SV versus $\mathrm{MD} / \mathrm{ML}$ & 0.0089 & 2.8080 & 1.2991 to 6.0695 \\
\hline \multirow[t]{4}{*}{$+3142 \mathrm{G}-\mathrm{G}$} & ML versus C & 0.0499 & 2.3810 & 1.0405 to 5.4482 \\
\hline & SV versus ML & 0.0166 & 0.3048 & 0.1213 to 0.7658 \\
\hline & SV/MD versus $\mathrm{ML}$ & 0.0413 & 0.3825 & 0.1612 to 0.9079 \\
\hline & SV versus $\mathrm{MD} / \mathrm{ML}$ & 0.0108 & 0.3537 & 0.1603 to 0.7805 \\
\hline \multirow[t]{5}{*}{$+3142 \mathrm{C}$} & ML versus $\mathrm{C}$ & $0.0006^{*}$ & 0.1270 & 0.0296 to 0.5451 \\
\hline & SV versus ML & 0.0038 & 2.6939 & 1.3468 to 5.3884 \\
\hline & MD versus $\mathrm{ML}$ & 0.0306 & 2.5373 & 1.0778 to 5.9728 \\
\hline & SV/MD versus $M L$ & $0.0006^{*}$ & 8.4460 & 1.9439 to 36.6940 \\
\hline & SV versus $\mathrm{MD} / \mathrm{ML}$ & 0.0310 & 1.8214 & 1.0577 to 3.1367 \\
\hline \multirow[t]{5}{*}{$+3142 \mathrm{G}$} & ML versus $\mathrm{C}$ & $0.0006^{*}$ & 7.8750 & 1.8347 to 33.8016 \\
\hline & SV versus ML & 0.0038 & 0.4309 & 0.2203 to 0.7658 \\
\hline & MD versus ML & 0.0306 & 0.4035 & 0.1712 to 0.9511 \\
\hline & SV/MD versus $M L$ & $0.0006^{*}$ & 0.1184 & 0.0273 to 0.5144 \\
\hline & SV versus $\mathrm{MD} / \mathrm{ML}$ & 0.0310 & 0.5490 & 0.3188 to 0.9455 \\
\hline$+3187 \mathrm{G}-\mathrm{G}$ & SV versus $\mathrm{MD}$ & 0.0118 & 0.0664 & 0.0070 to 0.6336 \\
\hline \multirow[t]{3}{*}{$+3187 \mathrm{G}$} & ML versus C & 0.0403 & 0.4200 & 0.1887 to 0.9347 \\
\hline & MD versus ML & 0.0276 & 3.1250 & 1.1679 to 8.3614 \\
\hline & SV/MD versus ML & 0.0493 & 2.2820 & 1.0060 to 5.1770 \\
\hline \multirow[t]{3}{*}{$+3187 \mathrm{~A}$} & ML versus $C$ & 0.0403 & 2.3810 & 1.0699 to 5.2987 \\
\hline & MD versus ML & 0.0276 & 0.3200 & 0.1196 to 0.8562 \\
\hline & SV/MD versus $\mathrm{ML}$ & 0.0493 & 0.4383 & 0.1931 to 0.9944 \\
\hline
\end{tabular}

Abbreviations: HLA-G: Human Antigen Leukocyte-G; C: healthy individuals; W: whole group of asthmatic patients; ML: mild asthmatic patients; MD: moderate asthmatic patients; SV: severe asthmatic patients; MD/SV: moderate and severe asthmatic patients group; ML/MD: mild and moderate asthmatic patients group; OR: odds ratio; 95\% CI: 95\% Confidence Interval; for alleles.

*Significant results after Bonferroni's correction for multiple tests involving genotypes and alleles highlighting in bold: $\alpha c=0.0014$ for genotypes and $\alpha c=0.0020$.

\subsection{Statistical analysis}

Differences among patient characteristics according to asthma severity were performed using the Kruskal-Wallis test followed by the Dunn post hoc test. Total IgE levels and spirometry values were compared by the Chi-square test using the GraphPad Prism 5.0 software (Table 1).

Allele and genotype frequencies at each variable site were estimated by direct counting. Adherences of genotypic proportions to HardyWeinberg equilibrium (HWE) expectations were estimated by the exact test of Guo and Thompson, using the ARLEQUIN 3.5.1.2 software (Excoffier and Lischer, 2010). Linkage disequilibrium (LD) between each pair of loci was evaluated for each group by means of a likelihood ratio test of linkage disequilibrium, implemented by HAPLOVIEW program (Barrett et al., 2005).

Data for control subjects have been previously phased into extended haplotypes as described elsewhere (Castelli et al., 2017). For patients, given the positive LD between alleles, but unknown gametic phase, haplotypes were reconstructed for each individual using a coalescencebased method implemented by the PHASE v2 software (Stephens et al., 2001). Ten independent runs were performed and the following configurations were used: random seed values for each run, number of interactions set to 1000 , thinning interval set to 1 , and burn-in value set to 100 .

We constructed $2 \times 2$ contingency tables to compare the frequency of each allele, genotype or haplotype between patients and controls. $P$ values were calculated by the two-sided Fisher exact test, using the GraphPad Prism 5.0 software, which was also used to estimate the Odds Ratio (OR) and its 95\% Confidence Interval (95\%CI). For all analyses, $P$-values were considered to be significant at a 0.05 significance level $(\alpha=0.05)$. The correction for multiple tests was performed using the Bonferroni procedure, which resulted in adjusted significance levels of $\alpha_{c}=0.0014$ for genotypes, $\alpha_{c}=0.0020$ for alleles and $\alpha_{c}=0.0036$ for haplotypes, according to the equation $\alpha_{c}=0.05 / n$, in which $n$ corresponds to the total number of genotypes $(n=36)$, alleles $(n=24)$ or haplotypes $(n=14)$ analyzed. The OR was used as association measure between multiple comparisons, for which an $\mathrm{OR} \geq 1.0$ was associated with susceptibility to disease development and an $\mathrm{OR} \leq 1.0$ conferred protection against disease development.

\section{Results}

Considering patients and controls, we observed twelve variation sites along the HLA-G 3 'UTR segment, including the 14-bp-Del/Ins (rs66554220) and the following single nucleotide polymorphisms (SNPs): +3001C/T (rs567747015), +3003T/C (rs115689421), +3010C/G (rs116152775), +3027C/A (rs115810666), +3032G/C (rs146339774), $\quad+3035 \mathrm{C} / \mathrm{T} \quad(\mathrm{rs} 115100128), \quad+3121 \mathrm{~T} / \mathrm{C}$ (rs138249160), +3142G/C (rs115928989), $+3187 \mathrm{~A} / \mathrm{G}$ $(\mathrm{rs} 114317070),+3196 \mathrm{C} / \mathrm{G} \quad(\mathrm{rs} 115045214)$ and $+3227 \mathrm{G} / \mathrm{A}$ (rs1233331).

To evaluate whether 3'UTR polymorphisms were associated with asthma and disease severity, we compared allele, genotype and haplotype frequencies of the whole group of asthmatic patients with healthy controls. Subgroups of asthmatic patients, stratified according to disease severity (mild, moderate, severe asthma, and combined mild/ moderate and moderate/severe asthma) were compared to each other and with healthy controls.

The results revealed that most of the studied polymorphisms fit the Hardy-Weinberg equilibrium expectations (data not shown), except for the following polymorphisms: i) the $+3032 \mathrm{G} / \mathrm{C}$ in the whole asthma group $(P=0.0045)$, in patients with severe asthma $(P=0.0077)$, and in the moderate/severe asthma group $(P=0.0058)$; and ii) the $+3010 \mathrm{C} /$ $\mathrm{G}$ in the patients with moderate asthma $(P=0.0251)$ and in the mild/ moderate asthma group $(P=0.0469)$, exhibiting a deficit in heterozygosis for these variation sites.

Allele and genotype frequencies of all these polymorphic sites evaluated in this study are shown in Table 2. After allele, genotype and haplotype multiple comparisons, none of the HLA-G 3'UTR polymorphic sites was associated with asthma per se. In contrast, the comparisons of patients stratified according to disease severity revealed several associations as shown in Table 3; however, few associations remained significant after applying the Bonferroni's correction. Compared to healthy controls, the $+3142 \mathrm{G}$ allele was overrepresented in mild asthma $(P=0.0006, \quad \mathrm{OR}=7.8750,95 \% \mathrm{IC}=1.8340-33.8016)$. Regarding the comparisons among asthma subsets, we observed that compared to mild asthma: i) the $+3010 \mathrm{G}$ allele was overrepresented in patients with severe asthma $(P=0.0006, \quad$ OR $=3.4993, \quad 95 \%$ IC $=1.7122$ to 1.517 ) and in patients with moderate/severe asthma 


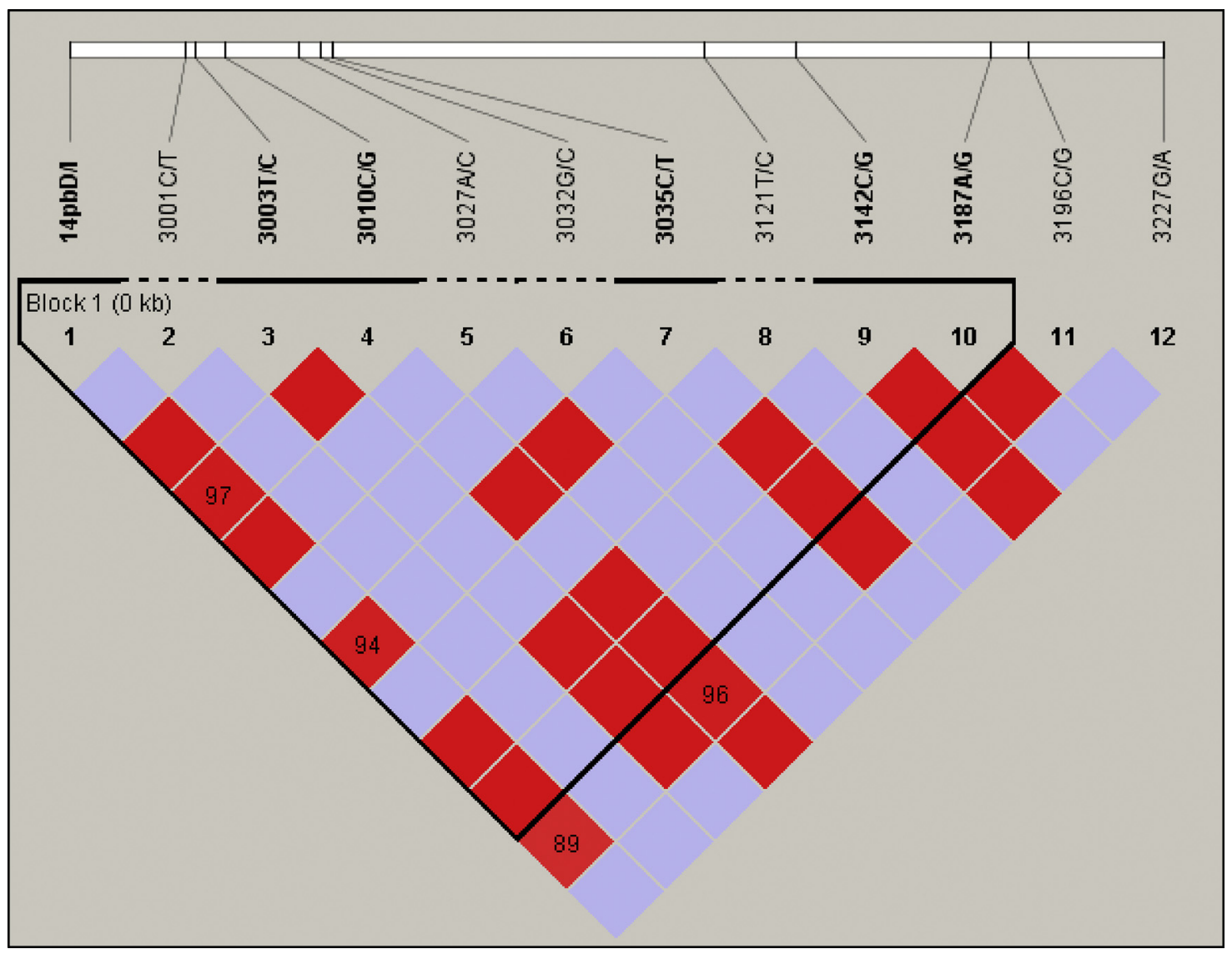

Fig. 1. Linkage disequilibrium ( $\left.D^{\prime}\right)$ plot of the HLA-G $3^{\prime}$ UTR segment in the whole asthmatic patient group. The Haploview program generated the images. Areas in dark red indicate strong LD (LOD $\geq 2, D^{\prime}=1$ ), shades of pink indicate moderate LD (LOD $\geq 2, D^{\prime}<1$ ), blue indicates weak LD (LOD $<2, D^{\prime}=1$ ), and white indicates no LD (LOD $<2, D^{\prime}<1$ ). The haplotype blocks were defined by the confidence interval method implemented by Haploview (Barrett et al., 2005). $D^{\prime}$ values different from 1.00 are represented inside the squares as percentages. LOD, log of the odds; $D^{\prime}$, pairwise correlation between SNPs (For interpretation of the references to colour in this figure legend, the reader is referred to the web version of this article).

Table 4

Haplotype frequencies in patients with asthma stratified according to severity of disease and in healthy individuals.

\begin{tabular}{|c|c|c|c|c|c|c|c|c|c|c|c|c|c|c|c|c|c|c|c|c|c|c|c|c|c|c|}
\hline \multirow{3}{*}{ Haplotype } & \multirow{2}{*}{\multicolumn{12}{|c|}{ 3'UTR HLA-G variation sites }} & \multicolumn{14}{|c|}{ Groups } \\
\hline & & & & & & & & & & & & & \multicolumn{2}{|r|}{ c } & \multicolumn{2}{|c|}{ w } & \multicolumn{2}{|r|}{ ML } & \multicolumn{2}{|r|}{ MD } & \multicolumn{2}{|r|}{ sv } & \multicolumn{2}{|c|}{ MD/SV } & \multicolumn{2}{|c|}{ ML/MD } \\
\hline & & & & & & & & & & & & & $n$ & Freq. & $n$ & Freq. & $n$ & Freq. & $n$ & Freq. & $n$ & Freq. & $n$ & Freq. & $n$ & Freq. \\
\hline & 14-bp & 3001 & 3003 & 3010 & 3027 & 3032 & 3035 & 3121 & 3142 & 3187 & 3196 & 3227 & & $n=232$ & & $=230$ & & $2 n=58$ & & $2 n=42$ & & $p=130$ & & $n=172$ & & $p=100$ \\
\hline UTR-1 & Del & c & $T$ & G & c & G & c & T & c & G & c & G & 64 & $0.2759^{*}$ & 54 & 0.2348 & 8 & $0.1379^{*}$ & 14 & $0.3333^{*}$ & 32 & 0.2462 & 46 & $0.2674^{*}$ & 22 & 0.2200 \\
\hline UTR-2 & Ins & c & $T$ & c & c & G & c & $\mathrm{T}$ & G & A & G & G & 63 & 0.2716 & 61 & 0.2652 & 17 & 0.2931 & 14 & 0.3333 & 30 & 0.2308 & 44 & 0.2558 & 31 & 0.3100 \\
\hline UTR-3 & Del & c & T & c & c & G & c & T & G & A & C & G & 30 & $0.1293^{*}$ & 39 & 0.1696 & 17 & $0.2931^{*}$ & 4 & $0.0952^{*}$ & 18 & 0.1385 & 22 & $0.1279^{*}$ & 21 & 0.2100 \\
\hline UTR-4 & Del & C & c & G & c & G & C & $\mathrm{T}$ & C & A & c & G & 31 & 0.1336 & 23 & 0.1000 & 2 & 0.0345 & 5 & 0.1190 & 16 & 0.1231 & 21 & 0.1221 & 7 & 0.0700 \\
\hline UTR-5 & Ins & c & T & c & c & G & T & $\begin{array}{ll}\mathrm{T} \\
\mathrm{f}\end{array}$ & G & A & c & G & 19 & 0.0819 & 23 & 0.1000 & 8 & 0.1379 & 2 & 0.0476 & 13 & 0.1000 & 15 & 0.0872 & 10 & 0.1000 \\
\hline UTR-6 & Del & C & $\begin{array}{ll}\mathrm{T} \\
\text {. }\end{array}$ & G & c & G & c & T & c & A & c & G & 4 & 0.0172 & 6 & 0.0261 & 0 & 0.0000 & 0 & 0.0000 & 6 & 0.0462 & 6 & 0.0349 & 0 & 0.0000 \\
\hline UTR-7 & Ins & c & $\begin{array}{ll}T \\
\text { T }\end{array}$ & C & A & G & T & $\begin{array}{ll}T \\
T\end{array}$ & G & A & c & G & 13 & 0.0560 & 6 & 0.0261 & 0 & 0.0000 & 3 & 0.0714 & 3 & 0.0231 & 6 & 0.0349 & 3 & 0.0300 \\
\hline UTR-8 & Ins & c & T & G & c & G & c & $\mathrm{T}$ & G & A & G & G & 0 & 0.0000 & 1 & 0.0043 & 0 & 0.0000 & 0 & 0.0000 & 1 & 0.0077 & 1 & 0.0058 & 0 & 0.0000 \\
\hline UTR-10 & Del & C & T & C & C & G & C & $\begin{array}{ll}\mathrm{T} \\
\mathrm{T}\end{array}$ & G & A & G & G & 0 & 0.0000 & 4 & 0.0174 & 1 & 0.0172 & 0 & 0.0000 & 3 & 0.0231 & 3 & 0.0174 & 1 & 0.0100 \\
\hline UTR-13 & Del & c & $\begin{array}{ll}\mathrm{T} \\
\mathrm{f}\end{array}$ & C & C & G & T & $\begin{array}{ll}T \\
\text { s }\end{array}$ & G & A & C & G & 0 & 0.0000 & 1 & 0.0043 & 1 & 0.0172 & 0 & 0.0000 & 0 & 0.0000 & 0 & 0.0000 & 1 & 0.0100 \\
\hline UTR-17 & Ins & T & $\begin{array}{ll}T \\
\end{array}$ & c & c & G & T & $\mathrm{T}$ & G & A & C & G & 2 & 0.0086 & 2 & 0.0087 & 1 & 0.0172 & 0 & 0.0000 & 1 & 0.0077 & 1 & 0.0058 & 1 & 0.0100 \\
\hline UTR-18 & Del & C & $\begin{array}{ll}T \\
\end{array}$ & G & C & G & C & $T$ & C & A & c & A & 5 & 0.0216 & 7 & 0.0304 & 3 & 0.0517 & 0 & 0.0000 & 4 & 0.0308 & 4 & 0.0233 & 3 & 0.0300 \\
\hline UTR-20 & Del & c & $\begin{array}{ll}T \\
\end{array}$ & G & c & C & C & $\begin{array}{ll}\mathrm{T} \\
\mathrm{f}\end{array}$ & c & A & c & G & 0 & 0.0000 & 2 & 0.0087 & 0 & 0.0000 & 0 & 0.0000 & 2 & 0.0154 & 1 & 0.0058 & 0 & 0.0000 \\
\hline UTR-44 & Ins & c & T & c & c & G & $T$ & c & G & A & c & G & 1 & 0.0043 & 1 & 0.0043 & 0 & 0.0000 & 0 & 0.0000 & 1 & 0.0077 & 2 & 0.0116 & 0 & 0.0000 \\
\hline
\end{tabular}

$(P=0.0012, \quad$ OR $=3.3021, \quad 95 \% \mathrm{IC}=1.6543-6.5909), \quad$ and ii $)$ the $+3142 \mathrm{G}$ allele was underrepresented in patients with moderate/severe asthma group $(P=0.0006, \mathrm{OR}=0.1184,95 \% \mathrm{IC}=0.0273$ to 0.5144$)$.

Overall, positive linkage disequilibrium (LD) was observed for most loci in patients (Fig. 1), allowing the application of computational haplotype inference procedures. Haplotypes were inferred by PHASE in all samples with an average probability of 1.0. Fourteen different HLA$G$ 3'UTR haplotypes were observed in the total sample, and about $50 \%$ of these haplotypes presented frequencies higher than or equal to $2 \%$ (Table 4). Haplotypes were named according the nomenclature previously proposed by our group (Castelli et al., 2017 2010). Although haplotype associations were observed as shown in Table 4, significance was lost after applying the Bonferroni correction for multiple comparisons $\left(\alpha_{c}=0.0036\right)$.

\section{Discussion}

The regulatory regions of the $H L A-G$ gene present several polymorphic sites, potentially related to protein production, which may contribute to susceptibility to or protection against inflammatory and 
non-inflammatory disorders. In fact, differential frequencies of polymorphic sites at HLA-G $3^{\prime}$ UTR have been reported in autoimmune diseases, organ transplantation outcome, viral infections, parasitic disorders and cancer, among other diseases (Ciliao Alves et al., 2012; Dias et al., 2015; Donadi et al., 2011; Silva et al., 2013). Few studies have evaluated the association of asthma with the $H L A-G$ regulatory region polymorphic sites (Nicolae et al., 2005; Tan et al., 2008; Zheng et al., 2010), however, none of these studies evaluated the entire HLA-G 3'UTR segment in asthmatic patients stratified according to disease severity.

A genome-wide study reported that the promoter $H L A-G$-964G-G genotype conferred susceptibility to asthma development in children born from asthmatic mothers, while the -964A-A genotype was associated with susceptibility to asthma development in children born from non-asthmatic mothers (Nicolae et al., 2005). Regarding the HLA-G 3'UTR segment, few studies evaluated only the 14bp-Del/Ins (Tan et al., 2008; Zheng et al., 2010) and the +3142G/C (Nicodemus-Johnson et al., 2013; Tan et al., 2008) variation sites. The evaluation of the entire $H L A-G$ 3'UTR, as performed in this study, revealed several associations; however, only few remained significant after the correction for multiple comparisons, and these results were primarily associated with the +3010C/G (rs116152775) and +3142G/C (rs115928989) variation sites. Compared to healthy controls, the $+3142 \mathrm{G}$ allele was associated to mild asthma development, and comparisons among asthma subgroups revealed that $+3010 \mathrm{G}$ and the $+3142 \mathrm{C}$ alleles were overrepresented in patients with moderate or severe asthma when compared to mild asthma. In addition, the evaluation of the polymorphic sites observed at the HLA-G $3^{\prime}$ UTR did not reveal association with asthma per se.

The HLA-G + 3142G has been described as protective allele for asthmatic children born from asthmatic mothers, while the $H L A-G$ $+3142 \mathrm{C}$ allele was associated with susceptibility to asthma in children born from non-asthmatic mothers (Tan et al., 2008). Noteworthy, these authors also identified by functional studies that HLA-G + 3142G allele was associated with decreased HLA-G expression, due to the local action of specific miRNAs, including miR-148a, mIr-148b and miR-152 (Tan et al., 2008). These data corroborate another study which reported that adult asthmatic patients presenting the $+3142 \mathrm{G}$ allele exhibited lower soluble levels of HLA-G (sHLA-G) in bronchoalveolar fluid when compared to the $+3142 \mathrm{C}$ allele (Nicodemus-Johnson et al., 2013). In contrast, the evaluation of the differentially expressed miRNAs in bronchoalveolar fluid or bronchial epithelial cells obtained from asthmatic patients stratified according to disease severity disclosed no differential expression of the miR152 family (Jardim et al., 2012; Levänen et al., 2013; Martinez-Nunez et al., 2014). Regarding the association between protein expression and the variation sites at the $+3142 \mathrm{G} / \mathrm{C}$ polymorphism, healthy individuals bearing the $+3142 \mathrm{G}$ allele and +3142 G-G genotype exhibited decreased plasma levels of soluble HLAG (sHLA-G) (Martelli-Palomino et al., 2013). In asthmatic patients stratified according to disease severity, the sHLA-G levels were increased in mild asthma (White et al., 2010) and decreased in severe asthma (Rizzo et al., 2009). Then, considering that: i) the $+3142 \mathrm{G}$ allele was associated with lower expression of sHLA-G (NicodemusJohnson et al., 2013; Tan et al., 2008) due miR152 local action; ii) the $+3142 \mathrm{G}$ is a susceptible allele to mild asthma development, as observed in this study; iii) increased levels of sHLA-G have been observed in patients with mild asthma (White et al., 2010); and iv) miRNAs that can modulate sHLA-G production are not observed in mild asthma (HajSalem et al., 2015; Jardim et al., 2012; Levänen et al., 2013), we may infer that the high HLA-G expression in mild asthma may be due absence or low function of miRNAs that target the HLA-G $3^{\prime} \mathrm{UTR}$ $+3142 \mathrm{G} / \mathrm{C}$ variation site.

The $H L A-G+3010 \mathrm{C} / \mathrm{G}$ variation site has not been functionally evaluated in terms of mRNA stability or miRNA regulation; however, in silico studies have shown that the $+3010 \mathrm{G}$ allele may be targeted by four miRNAs (miR-5703, miR-193a-5p, miR-5001-5p and miR6510-5p) and the +3010 C by miR-5787 (Porto et al., 2015). The evaluation of the differentially expressed miRNAs in bronchoalveolar fluid or bronchial epithelial cells obtained from asthmatic patients stratified according to disease severity disclosed no differential expression of these miRNAs (Haj-Salem et al., 2015; Jardim et al., 2012; Levänen et al., 2013; Martinez-Nunez et al., 2014). In our study, the +3010G allele was a susceptibility factor to severe asthma development. Although, this allele, plus with the +3010GG genotype, have been associated with high sHLA-G levels in healthy individuals (Martelli-Palomino et al., 2013), the sHLA-G levels in severe asthmatic patients has been described as decreased (Rizzo et al., 2009), indicating that other transcriptional or posttranscriptional mechanisms may be involved on the pathogenesis of severe asthma besides miRNA level regulation.

Considering that the HLA-G $3^{\prime}$ UTR variable sites are in linkage disequilibrium, as shown by our study (Fig. 1) as well as by others (Castelli et al., 2011; Sabbagh et al., 2014), we further evaluated the role of the ensemble of these variable sites (3'UTR haplotypes) on susceptibility to asthma and on asthma severity. Although haplotype associations were observed, significance was lost after applying the Bonferroni correction for multiple tests, probably due to the small size of the subgroups. Similarly, variation sites observed at the $H L A-G$ promoter region are also in linkage disequilibrium with those at the 3'UTR (Castelli et al., 2011; Sabbagh et al., 2014). Noteworthy, the HLA-G $3^{\prime} \mathrm{UTR}+3142 \mathrm{G} / \mathrm{C}$ and the promoter $-964 \mathrm{C} / \mathrm{G}$ variation sites were in linkage disequilibrium in asthmatic children (Nicolae et al., 2005), corroborating the influence of other variation sites along the $H L A-G$ regulatory regions in asthma pathogenesis.

Concluding, the study of the 3'UTR segment of the HLA-G gene revealed that the $3010 \mathrm{C} / \mathrm{G}$ and $+3142 \mathrm{G} / \mathrm{C}$ variation sites were differentially associated with asthma severity.

\section{Conflict of interest}

The authors declare absence conflict of interest regarding this paper publication.

\section{Acknowledgements}

This work was supported by Brazilian financial agencies: CAPES (Coordenação de Aperfeiçoamento de Pessoal de Nível Superior2014) and CNPq (Conselho Nacional de Desenvolvimento Científico e Tecnológico, 304931/2014-1).

\section{References}

Barrett, J.C., Fry, B., Maller, J., Daly, M.J., 2005. Haploview: analysis and visualization of LD and haplotype maps. Bioinformatics 21, 263-265. https://doi.org/10.1093/ bioinformatics/bth457.

Bell, G.M., Reynolds, G., Isaacs, J.D., 2011. Biologic therapies in non-rheumatic diseases: lessons for rheumatologists? Nat. Rev. Rheumatol. 7, 507-516. https://doi.org/10. 1038/nrrheum.2011.106.

Castelli, E.C., Mendes-Junior, C.T., Deghaide, N.H.S., de Albuquerque, R.S., Muniz, Y.C.N., Simões, R.T., Carosella, E.D., Moreau, P., Donadi, Ea, 2010. The genetic structure of 3'untranslated region of the HLA-G gene: polymorphisms and haplotypes. Genes Immun. 11, 134-141. https://doi.org/10.1038/gene.2009.74.

Castelli, E.C., Mendes-Junior, C.T., Veiga-Castelli, L.C., Roger, M., Moreau, P., Donadi, Ea., 2011. A comprehensive study of polymorphic sites along the HLA-G gene: implication for gene regulation and evolution. Mol. Biol. Evol. 28, 3069-3086. https:// doi.org/10.1093/molbev/msr138.

Castelli, E.C., Gerasimou, P., Paz, M.A., Ramalho, J., Porto, I.O.P., Lima, T.H.A., Souza, A.S., Veiga-Castelli, L.C., Collares, C.V.A., Donadi, E.A., Mendes-Junior, C.T., Costeas, P., 2017. HLA-G variability and haplotypes detected by massively parallel sequencing procedures in the geographicaly distinct population samples of Brazil and Cyprus. Mol. Immunol. 83, 115-126. https://doi.org/10.1016/j.molimm.2017.01.020.

Ciliao Alves, D.C., de Oliveira Crispim, J.C., Castelli, E.C., Mendes-Junior, C.T., Deghaide, N.H., Barros Silva, G.E., Costa, R.S., Saber, L.T., Moreau, P., Donadi, E.A., 2012. Human leukocyte antigen-G 3' untranslated region polymorphisms are associated with better kidney allograft acceptance. Hum. Immunol. 73, 52-59. https://doi.org/ 10.1016/j.humimm.2011.10.007.

Dias, F.C., Castelli, E.C., Collares, C.Va., Moreau, P., Donadi, Ea., 2015. The role of HLA-G molecule and HLA-G gene polymorphisms in tumors, viral hepatitis, and parasitic diseases. Front. Immunol. 6, 2-11. https://doi.org/10.3389/fimmu.2015.00009. 
Donadi, Ea., Castelli, E.C., Arnaiz-Villena, A., Roger, M., Rey, D., Moreau, P., 2011. Implications of the polymorphism of HLA-G on its function, regulation, evolution and disease association. Cell. Mol. Life Sci. 68, 369-395. https://doi.org/10.1007/ s00018-010-0580-7.

Excoffier, L., Lischer, H.E.L., 2010. Arlequin suite ver 3.5: a new series of programs to perform population genetics analyses under Linux and Windows. Mol. Ecol. Resour. 10, 564-567. https://doi.org/10.1111/j.1755-0998.2010.02847.x.

Gauthier, M., Ray, A., Wenzel, S.E., 2015. Evolving concepts of asthma. Am. J. Respir. Crit. Care Med. 192. https://doi.org/10.1164/rccm.201504-0763PP.

Global Initiative for Asthma, 2017. Global Strategy for Asthma Management and Prevetion. Avaible from:. www.ginasthma.org.

Haj-Salem, I., Fakhfakh, R., Berube, J.-C., Jacques, E., Plante, S., Simard, M.J., Bosse, Y., Chakir, J., 2015. MicroRNA-19a enhances proliferation of bronchial epithelial cells by targeting TGFbetaR2 gene in severe asthma. Allergy 70, 212-219. https://doi.org/ 10.1111/all.12551.

Holgate, S.T., 2012. Innate and adaptive immune responses in asthma. Nat. Med. 18, 673-683. https://doi.org/10.1038/nm.2731.

Jardim, M.J., Dailey, L., Silbajoris, R., Diaz-Sanchez, D., 2012. Distinct microRNA expression in human airway cells of asthmatic donors identifies a novel asthma-associated gene. Am. J. Respir. Cell Mol. Biol. 47, 536-542. https://doi.org/10.1165/ rcmb.2011-01600C.

Kuhlen, J.L., Wahlquist, A.E., Nietert, P.J., Bains, S.N., 2014. Identification of asthma phenotypes in a tertiary care medical center. Am. J. Med. Sci. 348, 480-485.

Lee, J., Kim, J.D., Park, C., 2015. Gene-environment interactions in asthma: genetic and epigenetic effects. Yonsei Med. J. 56, 877-886.

Levänen, B., Bhakta, N.R., Torregrosa Paredes, P., Barbeau, R., Hiltbrunner, S., Pollack, J.L., Sköld, C.M., Svartengren, M., Grunewald, J., Gabrielsson, S., Eklund, A., Larsson, B.M., Woodruff, P.G., Erle, D.J., Wheelock, Å.M., 2013. Altered microRNA profiles in bronchoalveolar lavage fluid exosomes in asthmatic patients. J. Allergy Clin. Immunol. 131. https://doi.org/10.1016/j.jaci.2012.11.039.

Martelli-Palomino, G., Pancotto, Ja., Muniz, Y.C., Mendes-Junior, C.T., Castelli, E.C., Massaro, J.D., Krawice-Radanne, I., Poras, I., Rebmann, V., Carosella, E.D., RouasFreiss, N., Moreau, P., Donadi, Ea., 2013. Polymorphic sites at the 3' untranslated region of the HLA-G gene are associated with differential hla-g soluble levels in the brazilian and french population. PLoS ONE 8, 1-10. https://doi.org/10.1371/ journal.pone.0071742.

Martinez-Nunez, R.T., Bondanese, V.P., Louafi, F., Francisco-Garcia, A.S., Rupani, H., Bedke, N., Holgate, S., Howarth, P.H., Davies, D.E., Sanchez-Elsner, T., 2014. A microRNA network dysregulated in asthma controls IL-6 production in bronchial epithelial cells. PLoS ONE 9. https://doi.org/10.1371/journal.pone.0111659.

Morandi, F., Rizzo, R., Fainardi, E., Rouas-Freiss, N., Pistoia, V., 2016. Recent advances in our understanding of HLA-G biology: lessons from a wide spectrum of human diseases. J. Immunol. Res. 2016. https://doi.org/10.1155/2016/4326495.

Nicodemus-Johnson, J., Laxman, B., Stern, R.K., Sudi, J., Tierney, C.N., Norwick, L., Hogarth, D.K., McConville, J.F., Naureckas, E.T., Sperling, A.I., Solway, J., Krishnan, Ja., Nicolae, D.L., White, S.R., Ober, C., 2013. Maternal asthma and microRNA regulation of soluble HLA-G in the airway. J. Allergy Clin. Immunol. 131. https://doi. org/10.1016/j.jaci.2013.01.037.

Nicolae, D., Cox, N.J., Lester, La, Schneider, D., Tan, Z., Billstrand, C., Kuldanek, S.,
Donfack, J., Kogut, P., Patel, N.M., Goodenbour, J., Howard, T., Wolf, R., Koppelman, G.H., White, S.R., Parry, R., Postma, D.S., Meyers, D., Bleecker, E.R., Hunt, J.S., Solway, J., Ober, C., 2005. Fine mapping and positional candidate studies identify HLA-G as an asthma susceptibility gene on chromosome $6 \mathrm{p} 21$. Am. J. Hum. Genet. 76, 349-357. https://doi.org/10.1086/427763.

Porto, I.O.P., Mendes-Junior, C.T., Felício, L.P., Georg, R.C., Moreau, P., Donadi, Ea., Chies, J.A.B., Castelli, E.C., 2015. microRNAs targeting the immunomodulatory HLAG gene: a new survey searching for microRNAs with potential to regulate HLA-G. Mol. Immunol. 65, 230-241. https://doi.org/10.1016/j.molimm.2015.01.030.

Raundhal, M., Morse, C., Khare, A., Oriss, T.B., Milosevic, J., Trudeau, J., Huff, R., Pilewski, J., Holguin, F., Kolls, J., Wenzel, S., Ray, P., Ray, A., 2015. High IFN- $\gamma$ and low SLPI mark severe asthma in mice and humans. J. Clin. Invest. 125, 3037-3050. https://doi.org/10.1172/and.

Rizzo, R., Andersen, A.S., Lassen, M.R., Sørensen, H.C., Bergholt, T., Larsen, M.H., Melchiorri, L., Stignani, M., Baricordi, O.R., Hviid, T.V.F., 2009. Soluble Human Leukocyte Antigen-G isoforms in maternal plasma in early and late pregnancy. Am. J. Reprod. Immunol. 62, 320-338. https://doi.org/10.1111/j.1600-0897.2009. 00742.x.

Rousseau, P., Le Discorde, M., Mouillot, G., Marcou, C., Carosella, E.D., Moreau, P., 2003. The 14 bp deletion-insertion polymorphism in the $3^{\prime}$ UT region of the HLA-G gene influences HLA-G mRNA stability. Hum. Immunol. 64, 1005-1010. https://doi.org/ 10.1016/j.humimm.2003.08.347.

Sabbagh, a, Luisi, P., Castelli, E.C., Gineau, L., Courtin, D., Milet, J., Massaro, J.D., Laayouni, H., Moreau, P., Donadi, Ea, Garcia, A., 2014. Worldwide genetic variation at the 3' untranslated region of the HLA-G gene: balancing selection influencing genetic diversity. Genes Immun. 15, 95-106. https://doi.org/10.1038/gene.2013.67.

Silva, I.D., Muniz, Y.C.N., Sousa, M.C.P.S., Silva, K.R., Castelli, E.C., Filho, J.C.G., Osta, A.P., Lima, M.I.M., Simões, R.T., 2013. HLA-G 3'UTR polymorphisms in high grade and invasive cervico-vaginal cancer. Hum. Immunol. 74, 452-458. https://doi.org/ 10.1016/j.humimm.2012.11.025.

Stephens, M., Smith, N.J., Donnelly, P., 2001. A new statistical method for haplotype reconstruction from population data. Am. J. Hum. Genet. 68, 978-989. https://doi. org $/ 10.1086 / 319501$.

Tan, Z., Randall, G., Fan, J., Camoretti-Mercado, B., Brockman-Schneider, R., Pan, L., Solway, J., Gern, J.E., Lemanske, R.F., Nicolae, D., Ober, C., 2008. Allele-specific targeting of microRNAs to HLA-G and risk of asthma (PII:S0002-9297(07)63059-6). Am. J. Hum. Genet. 82 (251). https://doi.org/10.1016/j.ajhg.2007.12.008.

Wenzel, S.E., 2012. Asthma phenotypes: the evolution from clinical to molecular approaches. Nat. Med. 18, 716-725. https://doi.org/10.1038/nm.2678.

White, R.S., Loisel, D.A., McConvlle, J.F., Stern, R., Tu, Y.L., Marroquin, B.A., Noth, I., Ober, C., 2010. Levels of soluble HLA-G are increased in asthmatic airways. Eur. Respir. J. 35, 925-927. https://doi.org/10.1183/09031936.00164809.Levels.

Yie, S.M., Li, L.H., Xiao, R., Librach, C.L., 2008. A single base-pair mutation in the 3untranslated region of HLA-G mRNA is associated with pre-eclampsia. Mol. Hum Reprod. 14, 649-653. https://doi.org/10.1093/molehr/gan059.

Zheng, X.Q., Li, C.C., Xu, D.P., Lin, A., Bao, W.G., Yang, G.S., Yan, W.H., 2010. Analysis of the plasma soluble human leukocyte antigen-G and interleukin-10 levels in childhood atopic asthma. Hum. Immunol. 71, 982-987. https://doi.org/10.1016/j.humimm. 2010.06 .018$. 